\title{
Heavy ion linac as a high current proton beam injector
}

\author{
Winfried Barth, ${ }^{1,2}$ Aleksey Adonin, ${ }^{1}$ Sabrina Appel,${ }^{1}$ Peter Gerhard, ${ }^{1}$ \\ Manuel Heilmann, ${ }^{1}$ Frank Heymach, ${ }^{1}$ Ralph Hollinger, ${ }^{1}$ Wolfgang Vinzenz, \\ Hartmut Vormann, ${ }^{1}$ and Stepan Yaramyshev ${ }^{1}$ \\ ${ }^{1}$ GSI Helmholtzzentrum für Schwerionenforschung, Darmstadt, Germany \\ ${ }^{2}$ Helmholtz Institut Mainz, Germany \\ (Received 3 March 2015; published 18 May 2015)
}

\begin{abstract}
A significant part of the experimental program at Facility for Antiproton and Ion Research (FAIR) is dedicated to pbar physics requiring a high number of cooled pbars per hour. The primary proton beam has to be provided by a $70 \mathrm{MeV}$ proton linac followed by two synchrotrons. The new FAIR proton linac will deliver a pulsed proton beam of up to $35 \mathrm{~mA}$ of $36 \mu$ s duration at a repetition rate of $4 \mathrm{~Hz}$ (maximum). The GSI heavy ion linac (UNILAC) is able to deliver world record uranium beam intensities for injection into the synchrotrons, but it is not suitable for FAIR relevant proton beam operation. In an advanced machine investigation program it could be shown that the UNILAC is able to provide for sufficient high intensities of $\mathrm{CH}_{3}$ beam, cracked (and stripped) in a supersonic nitrogen gas jet into protons and carbon ions. This advanced operational approach will result in up to $3 \mathrm{~mA}$ of proton intensity at a maximum beam energy of $20 \mathrm{MeV}, 100 \mu$ s pulse duration and a repetition rate of up to $2.7 \mathrm{~Hz}$ delivered to the synchrotron SIS18. Recent linac beam measurements will be presented, showing that the UNILAC is able to serve as a proton FAIR injector for the first time, while the performance is limited to $25 \%$ of the FAIR requirements.
\end{abstract}

\section{INTRODUCTION}

Besides two ion source terminals and a low energy beam transport system (LEBT) the High Current Injector (HSI) [1] of the UNILAC (Fig. 1) comprises a $36 \mathrm{MHz}$ combination of Interdigital $\mathrm{H}$-structure and Radio Frequency Quadrupole (IH-RFQ) $(2.2 \mathrm{keV} / \mathrm{u}$ up to $120 \mathrm{keV} / \mathrm{u}$ ) and an Interdigital $\mathrm{H}$-structure Drift Tube Linac (IH-DTL), comprised of two separate tanks, accelerating the beam up to the final HSI energy of $1.4 \mathrm{MeV} / \mathrm{u}$. After stripping and charge state separation the Alvarez DTL provides for beam acceleration up to $\beta=0.155$. In the transfer line (TK) to the synchrotron SIS18 a foil stripper and another charge state separator system can be used. To provide the highest heavy ion beam currents $\left(15 \mathrm{emA}, \mathrm{U}^{28+}\right)$, as required for the Facility for Antiproton and Ion Research (FAIR) project [2], the GSI-HSI must deliver up to $2.8 \times 10^{12} \mathrm{U}^{4+}$ ions per pulse. Highly charged heavy ion beams as well as protons, both with high average intensities (but low pulse intensities), from an Electron Cyclotron Resonance (ECR) ion source of CAPRICE type are accelerated in the high charge state injector (HLI) comprising an RFQ and an $\mathrm{IH}$ resonator to $1.4 \mathrm{MeV} / \mathrm{u}$. The HLI as well as

Published by the American Physical Society under the terms of the Creative Commons Attribution 3.0 License. Further distribution of this work must maintain attribution to the author $(s)$ and the published article's title, journal citation, and DOI. the HSI serve in a time sharing mode for the main drift tube linac.

The new FAIR proton linac [3] has to provide the high intensity primary proton beam for the production of antiprotons. It will deliver a $70 \mathrm{MeV}$ beam to the SIS18 with a repetition rate of $4 \mathrm{~Hz}$. The room temperature linac will be located north of the existing UNILAC complex. The main beam parameters are listed in Table I.

The use of rf-coupled $\mathrm{CH}$ cavities $(<35 \mathrm{MeV})$ and single $\mathrm{CH}$ cavities $(35-70 \mathrm{MeV})$ is proved to be advantageous for a compact and efficient linac design (Fig. 2). Commissioning of the new proton linac is envisaged for the end of 2018.

Recently an advanced investigation program at the existing UNILAC was successfully pushed to deliver high intensity proton beams (up to the UNILAC space charge

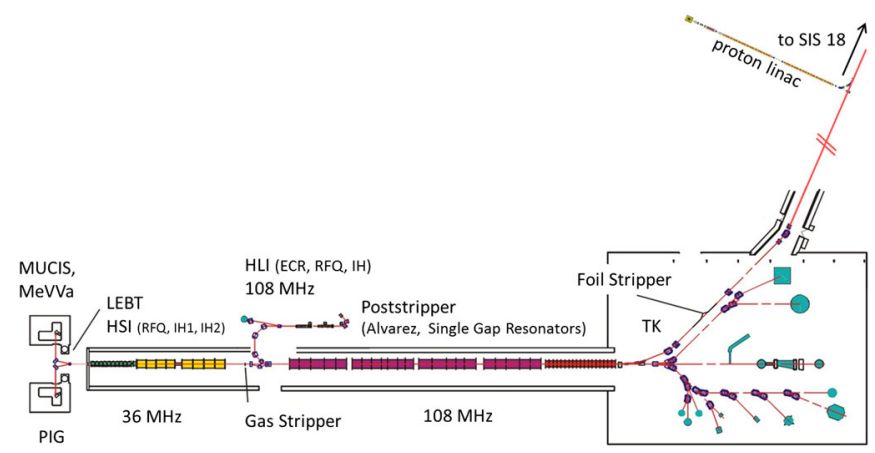

FIG. 1. Schematic overview of the GSI UNILAC, experimental area and new FAIR proton linac. 
TABLE I. Main parameters of the FAIR proton linac.

\begin{tabular}{lc}
\hline \hline & p-LINAC \\
\hline Final energy & $70 \mathrm{MeV}$ \\
Pulse current & $\mathrm{Up} \mathrm{to} 70 \mathrm{~mA}$ \\
Protons per pulse & $8 \times 10^{12}$ \\
Repetition rate & $4 \mathrm{~Hz}$ \\
Transversal beam emittance & $4.2 \mu \mathrm{m}$ (total normalized) \\
rf frequency & $325.224 \mathrm{MHz}$ \\
\hline \hline
\end{tabular}

limit) for a dedicated experimental program at SIS18. In this frame $\mathrm{CH}_{3}{ }^{+}$-beam operation with a multicusp ion source (MUCIS) was established. Besides, efforts were made for careful machine optimizations in all UNILAC sections, aiming for a high proton beam transmission and highest beam brilliance.

Special focus of investigation efforts was the gas stripper-and charge separator-section performance, where the molecules are cracked into protons and carbon ions and the separated high brilliance proton beam is matched to the Alvarez DTL. Proton beam acceleration and successful transport via the $120 \mathrm{~m}$ transfer line to the
SIS18 depends mainly on the accurate set up of the rf controls of the Alvarez high power supplies, operated at very low rf power.

\section{MACHINE DEVELOPMENT}

The MUCIS source [4] was operated with methane $\left(\mathrm{CH}_{4}\right)$ gas, while a high current $\mathrm{CH}_{3}{ }^{+}$-beam (3.0 emA) was delivered to the HSI. Due to the huge emittance in the LEBT only $50 \%$ of the $\mathrm{CH}_{3}{ }^{+}$beam could be accepted by the HSI-RFQ, minor additional particle losses in the matching section to the HSI-IH-DTL limits the overall HSI transmission to $45 \%$. Anyway, due to the higher HSI design limit (to fill the SIS18 up to the space charge limit) for $\mathrm{CH}_{3}{ }^{+}$-beam operation, the improved beam transmission compared to a pure proton beam is evident. Furthermore a triple particle output (for protons) from each $\mathrm{CH}_{3}{ }^{+}$molecule behind the stripping section allows for proton beam operation above the design limit of the poststripper linac (Fig. 3). For this, a machine investigation program was carried out to push the proton beam intensity; finally, in October 2014, a 30 times higher proton current was available. Strong efforts were

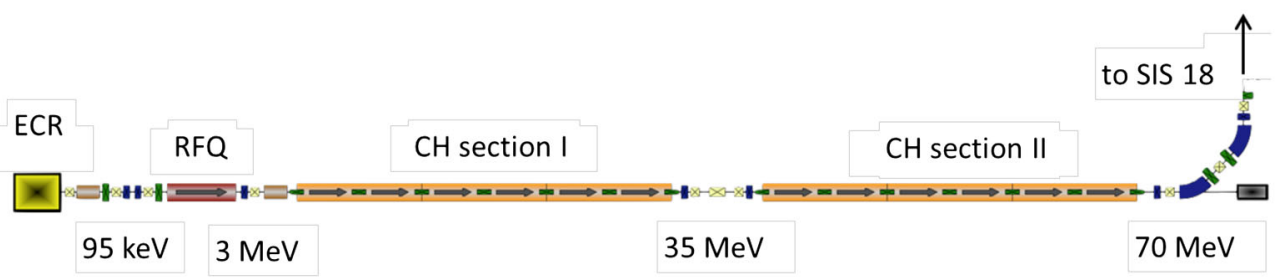

FIG. 2. Layout of the FAIR proton LINAC.

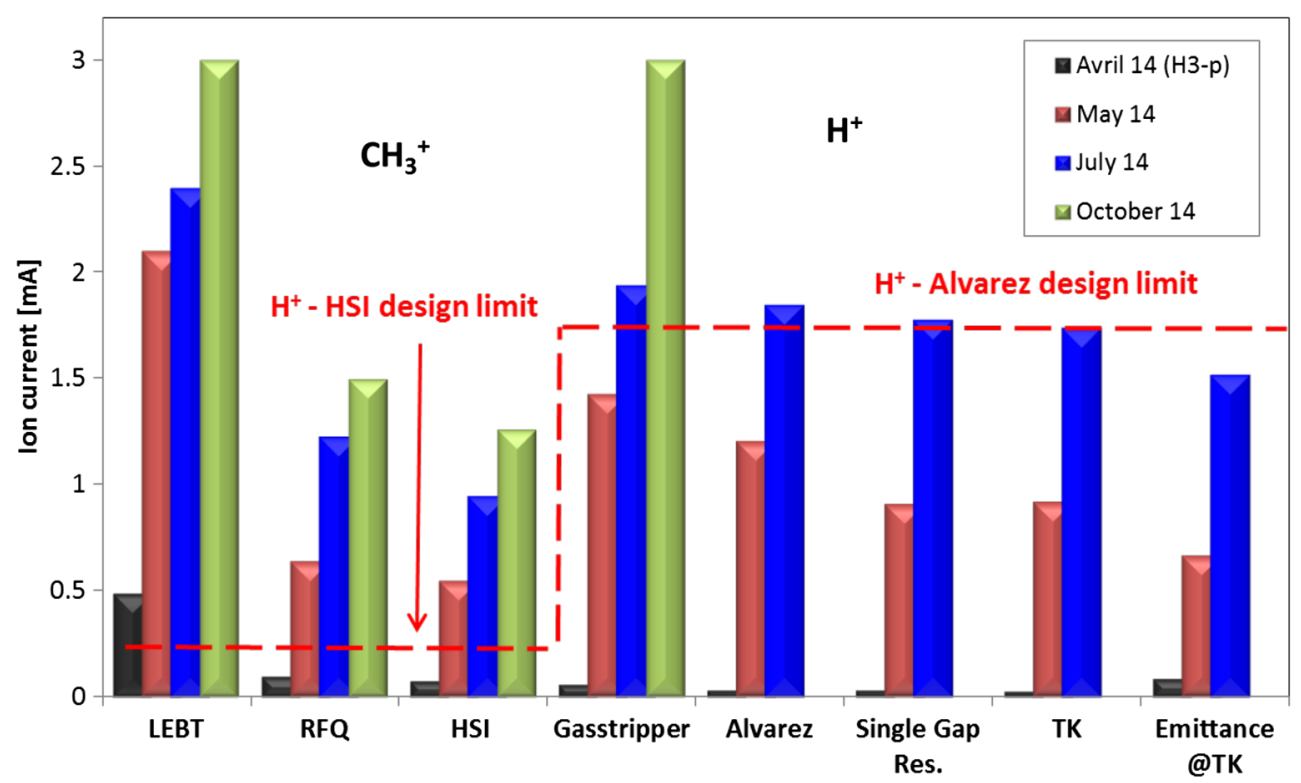

FIG. 3. Measured beam current along UNILAC and transfer line to the SIS18; the proton design limit was reached in the poststripper section. 
launched to push the high current proton beam transmission through the entire poststripper and transfer line to a value of up to $80 \%$ (for $2.0 \mathrm{~mA}$ ), mainly limited by the narrow aperture of a bending dipole inside the transfer line.

\section{ION SOURCE}

Another limitation for light ion beam operation is the low extraction voltage, applied at the ion source due to the fixed specific ion energy of $2.2 \mathrm{keV} / \mathrm{u}$ at the RFQ entrance. This limits strongly the extracted beam current from the ion source. However, an improvement is attainable by applying singly charged heavy (up to mass number 60) molecular ion beams with a high content of hydrogen atoms. For further investigations the first two elements from the alkane group, methane $\left(\mathrm{CH}_{4}\right)$ and ethane $\left(\mathrm{C}_{2} \mathrm{H}_{6}\right)$, have been considered. These substances are nontoxic, flammable gases that could be used in the ion sources under the same safety requirements as hydrogen gas.

The first experiments have been performed with methane gas used in a high current MUCIS ion source (Fig. 4). The plasma chamber of the MUCIS is equipped with an external magnetic coil, which allows to increase the plasma density in the extraction region and results in higher extracted beam current. The mass spectrum of the extracted beam is shown in Fig. 5. It contains several different molecule species (including higher order alkane chains). However, by tuning the operation parameters of the ion source, it was possible to optimize the spectrum and get the maximum output for $\mathrm{CH}_{3}{ }^{+}$ion contribution. The best ion beam formation was achieved at an extraction voltage of $9 \mathrm{kV}(24 \mathrm{kV}$ post acceleration voltage).

The maximum achieved beam current (for methane operation) was $11 \mathrm{~mA}$ for the not analyzed beam and $4 \mathrm{~mA}$ for the $\mathrm{CH}_{3}{ }^{+}$ion beam. The ion source operation was performed with a repetition frequency of $2 \mathrm{~Hz}$ and a

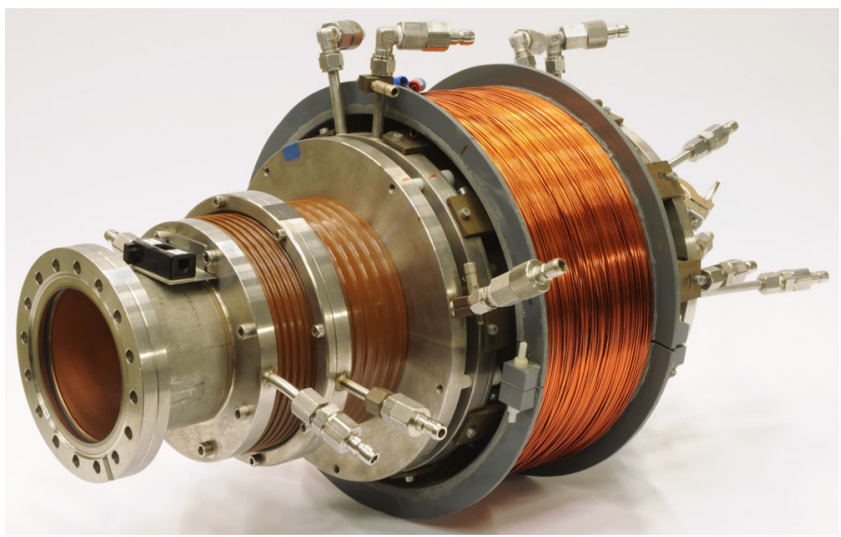

FIG. 4. The setup of the MUCIS ion source with external solenoid.
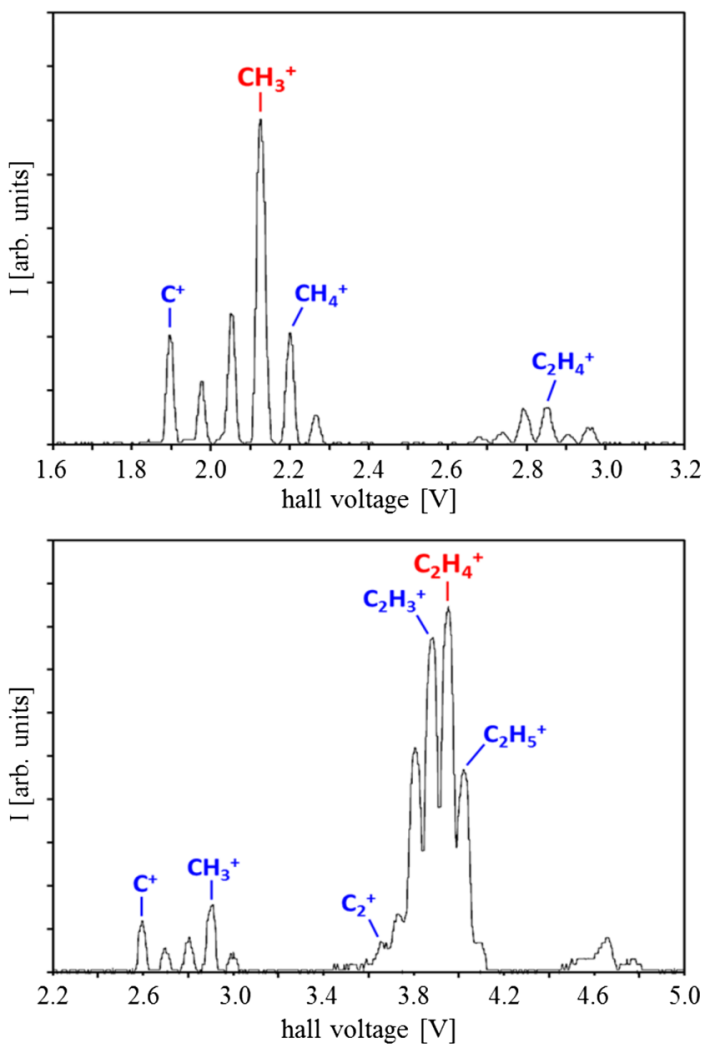

FIG. 5. Mass spectra from methane (upper) and ethane (lower) gas operation. The ion source settings were optimized for the production of $\mathrm{CH}_{3}{ }^{+}$and $\mathrm{C}_{2} \mathrm{H}_{4}{ }^{+}$respectively; the specific energy is fixed for $2.2 \mathrm{keV} / \mathrm{u}$ [5].

pulse length of $1 \mathrm{~ms}$. The ethane gas tests have been carried out with the same ion source and under the same conditions, but the mass spectrum is more complex than for methane operation (see Fig. 5). The production maximum was obtained for $\mathrm{C}_{2} \mathrm{H}_{4}{ }^{+}$, while a maximum beam current of $2.0 \mathrm{emA}$ in front of the RFQ was achieved. A direct comparison of $\mathrm{CH}_{3}^{+}$and $\mathrm{C}_{2} \mathrm{H}_{4}{ }^{+}$ operation behind the gas stripper is planned for the near future. However, assuming the same transmission through the HSI, $\mathrm{CH}_{3}{ }^{+}$-beam operation results in a significantly higher proton yield.

A notable disadvantage of the operation with $\mathrm{CH}_{4}$ and $\mathrm{C}_{2} \mathrm{H}_{6}$ gas is a strong and relatively fast contamination of the plasma chamber and the extraction system of the ion source with carbon. Carbon deposits on the extraction electrodes, as shown in Fig. 6, cause sparking and breakdowns in the extraction system. After several days of operation the carbon ions embedded in the heating filaments make them more fragile and reduce their durability and lifetime. Thus, the operation with alkanes requires a full service of the ion source with cleaning of the plasma chamber once a week. Different molecular ion species that have been tested aiming for intense proton beam production in the GSI UNILAC. As shown in 

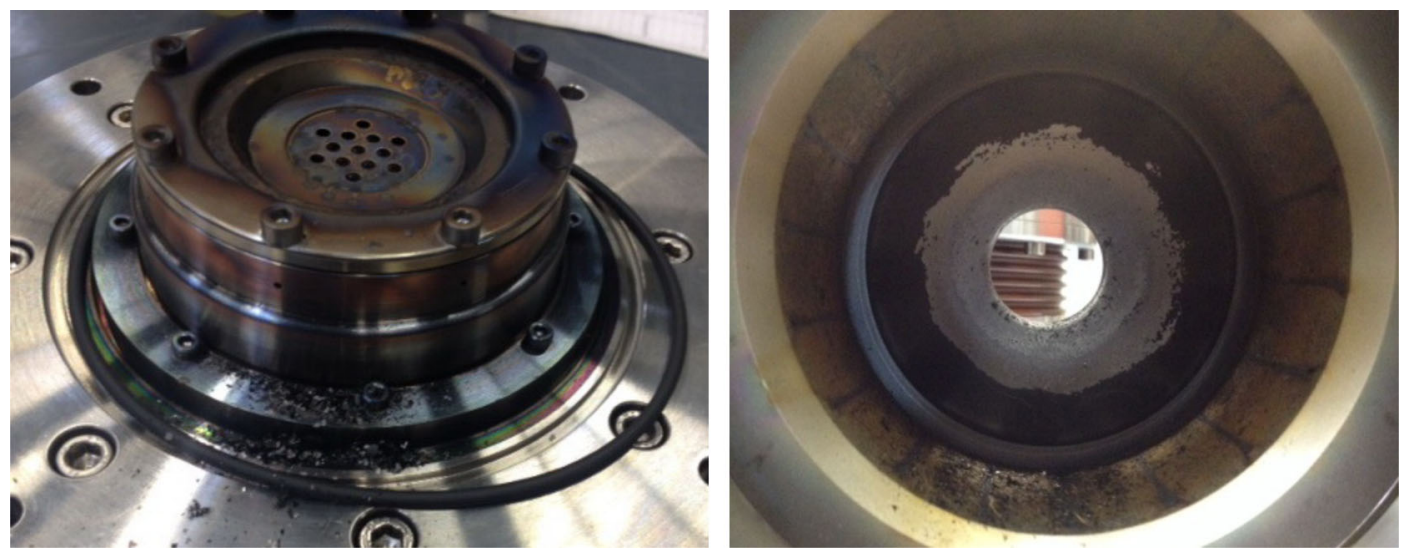

FIG. 6. Contamination of the extraction system (left) and the plasma chamber (right) of the ion source with carbon after six days of operation.

Table II, the best performance is recently achieved applying methane as an operating gas.

\section{GAS STRIPPER}

The gas stripper section [6] is located between the prestripper (HSI) and the poststripper linac (Alvarez). In the supersonic $\mathrm{N}_{2}$-gas jet the $\mathrm{CH}_{3}{ }^{+}$molecules are stripped and cracked in one carbon ion and three protons. In the charge separating system comprising three dipole magnets the high intensity proton beam is separated from the carbon beam. The measured charge spectrum (Fig. 7) shows a proton fraction, which is (above a certain threshold) independent on the density of the supersonic nitrogen gas jet target. The average charge of the carbon spectrum depends on the target density: A maximum at $Z=4$ for lower gas pressure and at $Z=5$ for highest gas pressure was observed. For advanced proton beam operation the lowest target density, providing for high beam intensities as well as for minimum beam straggling (minimum emittance growth), has been adjusted. The entire spectrum is influenced by the different secondary electron multiplying factors of proton and carbon beams; especially the relatively low measured proton beam current signal (compared to the carbon beam current signal) was not investigated in detail.

TABLE II. Beam currents achieved at $2.2 \mathrm{keV} / \mathrm{u}$ for various primary molecular beams.

\begin{tabular}{lccc}
\hline \hline Molecular ion species & $\mathrm{H}_{3}{ }^{+}$ & $\mathrm{CH}_{3}{ }^{+}$ & $\mathrm{C}_{2} \mathrm{H}_{4}{ }^{+}$ \\
\hline Gas & $\mathrm{H}_{2}$ & $\mathrm{CH}_{4}$ & $\mathrm{C}_{2} \mathrm{H}_{6}$ \\
\hline I [mA] @ion source terminal & 15 & 15 & 12 \\
I [mA] LEBT (total beam current) & 7 & 11 & 8 \\
I [mA] $@$ LEBT (analyzed) & 0.9 & 4 & 2 \\
\hline \hline
\end{tabular}

\section{SPECIAL RF ADJUSTMENTS}

Acceleration of protons at the UNILAC implicates special challenges for the settings of the high power $\mathrm{rf}$ sections. Designed and normally operated at rf levels between some $100 \mathrm{~kW}$ up to $2 \mathrm{MW}$, especially the low level part (amplitude and phase control) has to be adjusted to handle very low signal levels. The cavity voltage for the Alvarez tank 3, shown in Fig. 8, corresponds to an output power of approximately $21 \mathrm{~kW}$. The adjustment of the rise time setting has to ensure a constant gap voltage (flattop) at the time when the beam pulse is passing the cavity. The overall loop gain had to be increased up to a nonrisky level. Figure 8 shows the cavity voltage before (top) and after adjustment of the low level rf settings.

The reaction on the proton beam is shown in Fig. 9. Due to the lowered cavity impedance while the beam is present

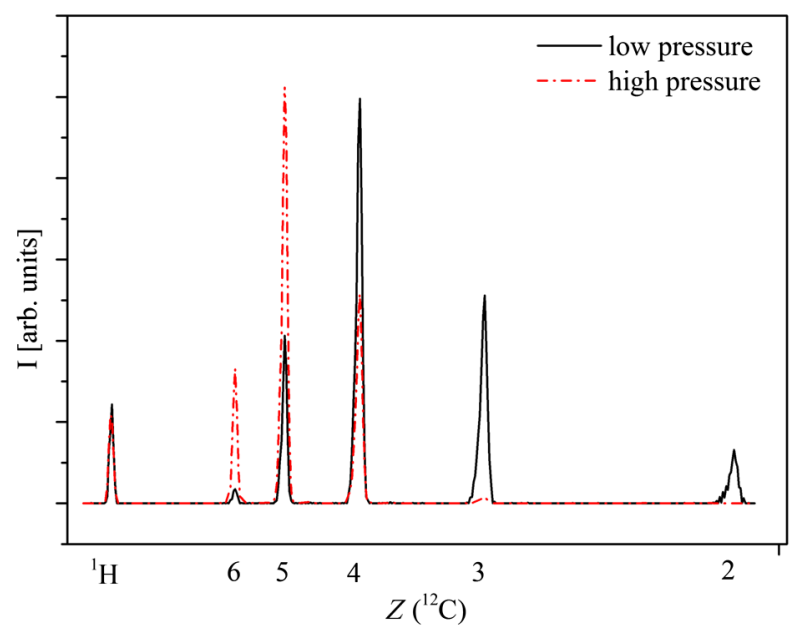

FIG. 7. Measured gas stripper spectrum of the $\mathrm{CH}_{3}{ }^{+}$beam from the HSI. Above a threshold (black) the proton beam intensity is independent on the $\mathrm{N}_{2}$-target density, while the carbon beam could be optimized for higher $Z$ (red) [5]. 

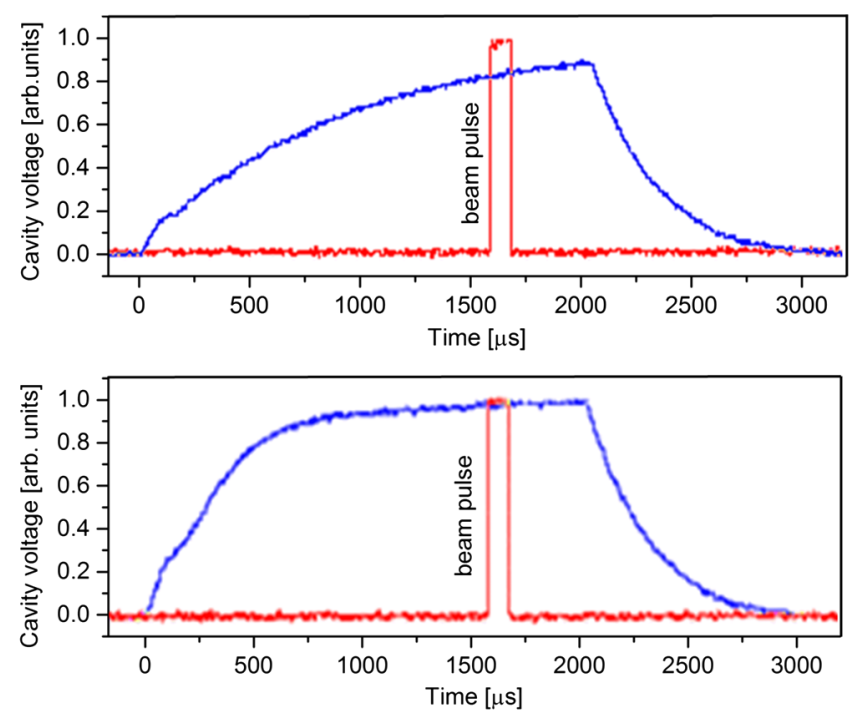

FIG. 8. Shape of the cavity voltage before (top) and after (bottom) optimization.

the control loop increases rf power in the range of $4 \mathrm{~kW}$ in addition to the $21 \mathrm{~kW}$ for the cavity losses.

\section{BEAM MEASUREMENTS}

The high current transverse beam emittance was measured with high resolution in all sections of the UNILAC and the transfer line (Fig. 10). The transverse emittance growth inside the entire Alvarez section could be minimized to $17 \%$ only. Even though a transmission loss was observed in the transfer line to the SIS18, the beam brilliance was kept constant during beam transport (Fig. 11). The bottleneck of the beam transport line is a

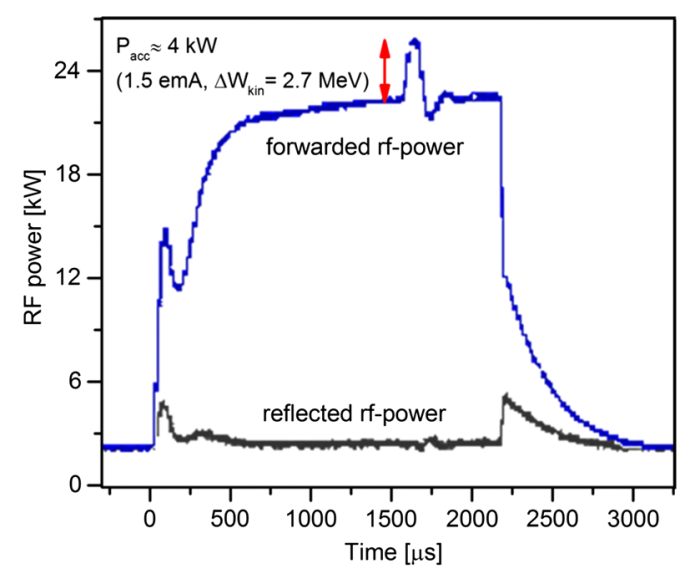

FIG. 9. Forward and reflected rf power; the impedance is decreased while the beam is entering the cavity. The low level control system regulates the rf amplifier to a higher forwarded $\mathrm{rf}$ power and compensates the beam dependent impedance drop (peak at $270 \mathrm{~ms}$ ).
22.5 degree bending magnet with a limited aperture implicating transmission loss of approximately $10 \%$ for high current proton beam operation.

\section{20 MeV PROTON BEAM}

The single-gap resonators are located behind the five Alvarez accelerators of the UNILAC. For all ion species the SGR provide for intermediate energies between 3.6 and $13.0 \mathrm{MeV} / \mathrm{u}$. During the high current experiment protons were preaccelerated in the UNILAC to a beam energy of $11.4 \mathrm{MeV} / \mathrm{u}$ (Fig. 12). Inside the following eight single gap resonators, each providing for an energy increase of more than $1 \mathrm{MV}$, a final energy of $20 \mathrm{MeV}$ could be reached (Fig. 13). This final energy corresponds to $28.5 \%$ of the FAIR proton linac energy. The energy is measured by the time-of-flight (TOF) method (Fig. 13). In the transfer channel the beam transmission can be specified with approximately $90 \%$ and thus $2.7 \mathrm{~mA}$ potentially can be injected into the synchrotron.

\section{OUTLOOK}

Besides optimizing the high current proton beam performance for the ongoing GSI experiment program, the UNILAC is able to serve as a high performance proton injector for FAIR commissioning and for first pbar experiments as a redundant option for the FAIR proton linac injector. In routine operation the UNILAC in combination with the SIS18 accelerated $2.1 \times 10^{11}$ protons per pulse (up to $2.5 \mathrm{GeV}$ ) for the first time, exceeding former peak records by more than 1 order of magnitude. A proton beam intensity of up to $2 \mathrm{~mA}$ was measured at full UNILAC beam energy of $11.4 \mathrm{MeV} / \mathrm{u}$, perspectively sufficient to deliver $9.2 \times 10^{11}$ protons per $80 \mu$ s pulse. Recently $3 \mathrm{~mA}$ were achieved behind the HSI and the stripper section at $1.4 \mathrm{MeV} / \mathrm{u}$. Higher proton intensities can be reached if the HSI is filled up to the design current limit (e.g., $4.5 \mathrm{emA}$ for $\mathrm{CH}_{3}{ }^{+}$). For this, a further ion source optimization campaign (improved extraction system for singly charged molecular beams) is envisaged. Besides, more heavy H-rich molecules [e.g., $\left(\mathrm{CH}_{3}\right)_{3} \mathrm{~N}$ ] could provide better transmission and higher yield of protons.

The measured UNILAC beam emittance is $60 \%$ lower than the FAIR proton linac design emittance; accordingly multiturn injection efficiency of SIS18 is higher. To meet the enhanced space charge limit in the SIS18 for higher injection energy, the linac beam current has to be increased appropriately. The GSI UNILAC (operating at $20 \mathrm{MeV}$ ) in combination with the SIS18 may serve as a high current proton injector for the new FAIR synchrotron SIS100 for up to $1.5 \times 10^{12}$ protons (Table III) and with up to $25 \%$ of the design proton beam intensity. 

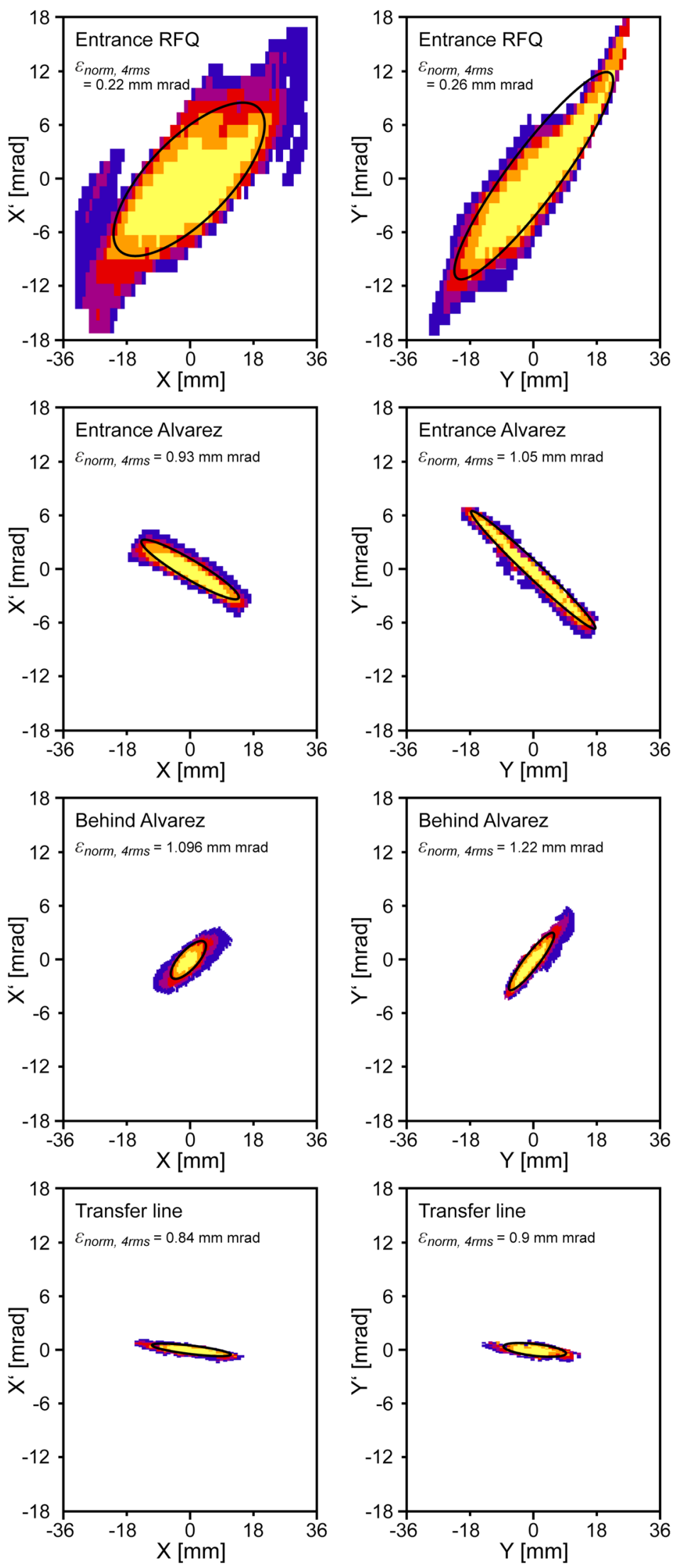

FIG. 10. Measured high current proton beam emittance [5]. 


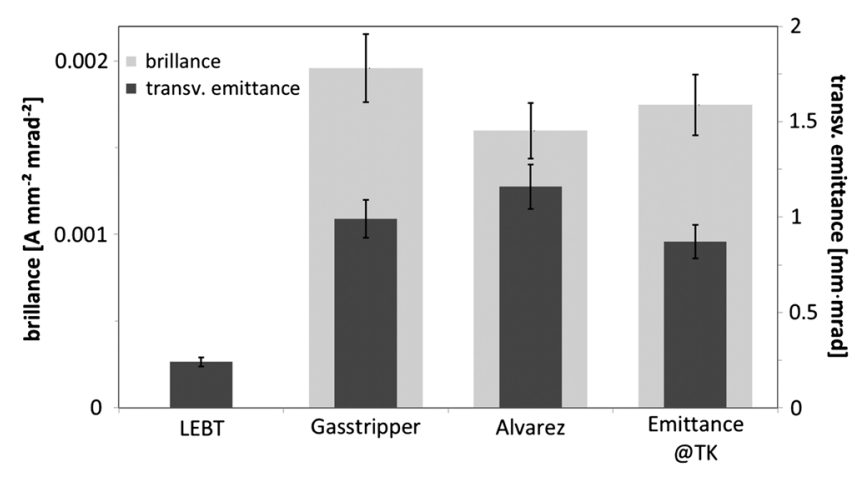

FIG. 11. Measured emittance growth and beam brilliance along the UNILAC [5].

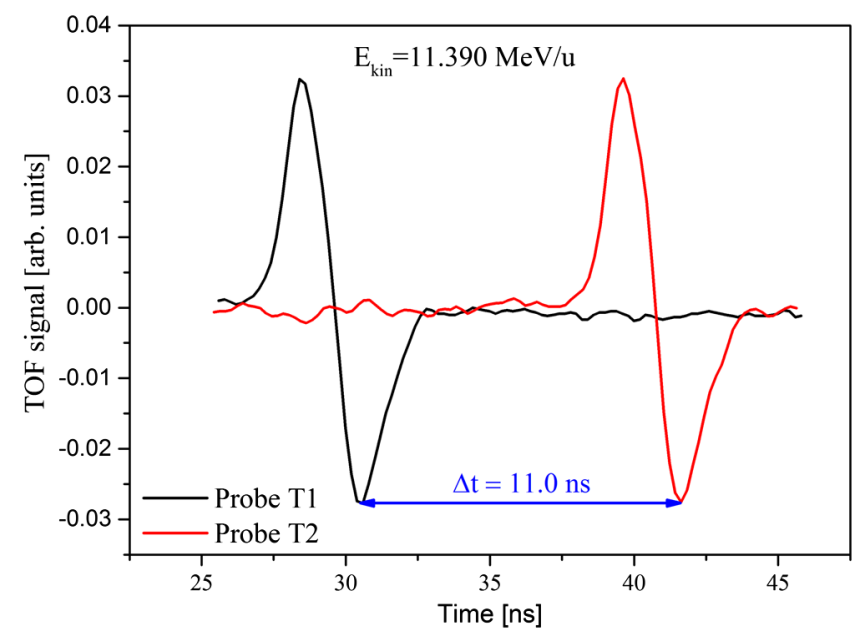

FIG. 12. Coarse measurement of the UNILAC proton beam energy applying the time-of-flight method with phase probe signals $(l=518.5 \mathrm{~mm}, \Delta t=11.0 \mathrm{~ns})$.

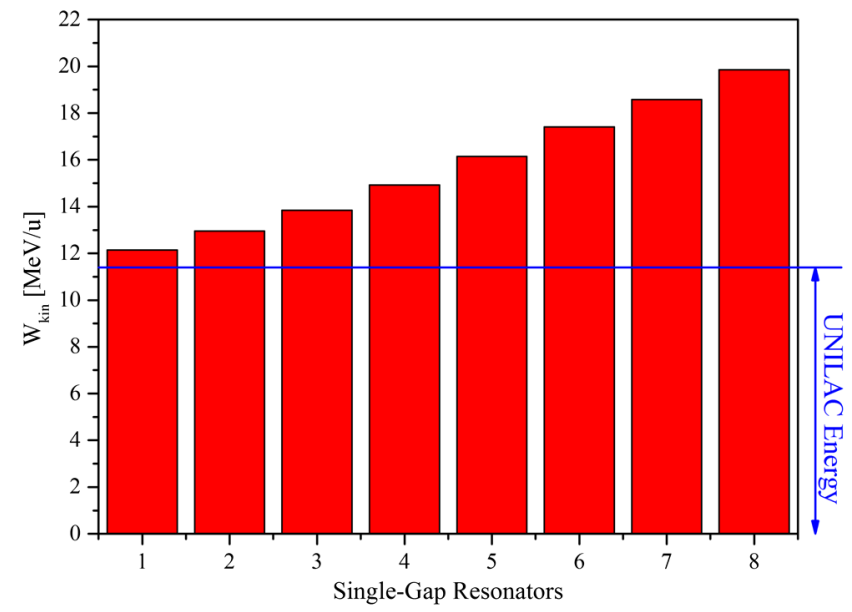

FIG. 13. UNILAC operation with eight single gap resonators for a maximum proton beam energy of $20 \mathrm{MeV}$.
TABLE III. Comparison of estimated intensities for different FAIR proton injector options [7-9]. Measured data are marked in bold.

\begin{tabular}{lcccc}
\hline \hline & p-LINAC & \multicolumn{3}{c}{ UNILAC } \\
\cline { 2 - 5 } & Design & \multicolumn{2}{c}{ Measurement } & Extrapolation \\
\hline $\mathrm{E}[\mathrm{MeV}]$ & 70 & $\mathbf{1 1 . 4}$ & $\mathbf{2 0}$ & 20 \\
$\mathrm{I}[\mathrm{mA}]$ & 35 & $\mathbf{2}$ & $\mathbf{2}$ & 3 \\
$\mathrm{E}_{\mathrm{x} \text { phys }} 4 \mathrm{rms}$ & 7 & $\mathbf{7}$ & $\mathbf{3}$ & 3 \\
$\quad[\mathrm{~mm}$ mrad] & & $\mathbf{8}$ & $\mathbf{3}$ & 3 \\
$\begin{array}{c}\mathrm{E}_{\mathrm{y} \text { phys }} 4 \mathrm{rms} \\
\quad[\mathrm{mm} \text { mrad] }\end{array}$ & 8 & $\mathbf{8}$ & & \\
$\begin{array}{c}\mathrm{SIS} 18 \mathrm{MTI} \\
\text { output (N) }\end{array}$ & $5.8 \times 10^{12}$ & $8.2 \times 10^{11}$ & $9.7 \times 10^{11}$ & $1.5 \times 10^{12}$ \\
$\begin{array}{c}\text { Space charge } \\
\text { limit (N) }\end{array}$ & $5.8 \times 10^{12}$ & $8.7 \times 10^{11}$ & $1.5 \times 10^{12}$ & $1.5 \times 10^{12}$ \\
$\begin{array}{c}\mathrm{SIS} 100 \\
\text { output }\end{array}$ & $1.8 \times 10^{13}$ & $2.4 \times 10^{12}$ & $2.9 \times 10^{12}$ & $4.5 \times 10^{12}$ \\
$\begin{array}{c}\text { SIS100 } \\
\text { output } \\
\text { (relative) }\end{array}$ & $100 \%$ & $13.0 \%$ & $16.0 \%$ & $25.0 \%$ \\
\hline \hline
\end{tabular}

\section{ACKNOWLEDGMENTS}

The authors are grateful for the support of the GSI ion source, linac, proton linac, rf, technical infrastructure and accelerator operation departments and operators from other GSI departments - a special thanks to Alexander Yakushev for numerous helpful discussions about ion source behavior and Brigitta Schausten supporting us by preparing emittance plots (Fig. 10).

[1] H. Vormann, W. Barth, L. Dahl, W. Vinzenz, S. Yaramyshev, U. Ratzinger, R. Tiede, A. Kolomiets, and S. Minaev, Advanced UNILAC upgrade for FAIR, in Proceedings of the 25th International Linear Accelerator Conference, LINAC-2010, Tsukuba, Japan (KEK, Tsukuba, Japan, 2010), p. 142.

[2] R. Brodhage, W. Vinzenz, G. Clemente, and U. Ratzinger, First coupled $\mathrm{CH}$ power cavity for the FAIR proton injector, in Proceedings of the 5th International Particle Accelerator Conference, IPAC-2014, Dresden, Germany (Dresden, Germany, 2014), p. 3232.

[3] O. Kester, W. Barth, O. Dolinskyy, F. Hagenbuck, K. Knie, H. Reich-Sprenger, H. Simon, P. J. Spiller, U. Weinrich, M. Winkler, R. Maier, and D. Prasuhn, Status of FAIR accelerator facility, in Proceedings of the 5th International Particle Accelerator Conference, IPAC-2014, Dresden, Germany (Dresden, Germany, 2014), p. 2084.

[4] R. Keller, Multicharged ion production with MUCIS, GSI Scientific. Report No. 1987, 1987, p. 385.

[5] W. Barth, A. Adonin, P. Gerhard, M. Heilmann, R. Hollinger, W. Vinzenz, and H. Vormann, High current proton beam operation at GSI UNILAC, in Proceedings of the 27th International Linear Accelerator Conference, LINAC-2014, Geneva, Switzerland (CERN, Geneva, Switzerland, 2014), p. 550 . 
[6] W. Barth and P. Forck, The new gas stripper, and charge state separator of the GSI high current injector, in Proceedings of the 20th International Linac Conference, LINAC2000, Monterey, CA, 2000 (SLAC, Menlo Park, CA, 2000), p. 235.

[7] S. Appel, O. Boine-Frankenheim, Multiturn injection into a heavy ion synchrotron in the presence of space charge, arXiv:1403.5972v1.
[8] U. Ratzinger, G. Clemente, C. Commenda, H. Liebermann, H. Podlech, R. Tiede, W. Barth, and L. Groening, A $70 \mathrm{MeV}$ proton linac for the FAIR facility based on $\mathrm{CH}$ cavities, in Proceedings of the 23rd International Linac Conference, LINAC-2006, Knoxville, TN, 2006 (JACoW, Knoxville, TN, 2006), p. 186.

[9] W. Vinzenz, p-linac status and plans, 12th FAIR Machine Advisory Committee (2014). 